\title{
Livestock 2.0 - genome editing for fitter, healthier, and more productive farmed animals
}

\author{
Christine Tait-Burkard, Andrea Doeschl-Wilson, Mike J. McGrew, Alan L. Archibald, Helen M. Sang, Ross D. Houston, \\ C. Bruce Whitelaw and Mick Watson ${ }^{*}$ (D)
}

\begin{abstract}
The human population is growing, and as a result we need to produce more food whilst reducing the impact of farming on the environment. Selective breeding and genomic selection have had a transformational impact on livestock productivity, and now transgenic and genome-editing technologies offer exciting opportunities for the production of fitter, healthier and more-productive livestock. Here, we review recent progress in the application of genome editing to farmed animal species and discuss the potential impact on our ability to produce food.
\end{abstract}

\section{Introduction}

There are an estimated 7.6 billion humans on the planet, yet an estimated one in nine of us (821 million people) do not have access to sufficient food to lead a normal, active life [1]. Despite the problems we face feeding our species, the human population is set to grow, reaching 8.5 billion in 2030, 9.7 billion in 2050 and 11.2 billion in 2100 [2]. Clearly, if we struggle to feed 7.5 billion people currently, preparing to feed almost 4 billion more will be one of the biggest challenges facing our species.

The FAO (Food and Agriculture Organization of the United Nations) has published estimates that total agricultural output, from both crops and animals, needs to increase by $60 \%$ in order to meet demand. Importantly, this is being driven by a higher demand for animal protein, with some estimates that milk production will need to increase by $63 \%$, and meat production by $76 \%$ [3]. This proportional increase in demand for animal products is largely driven by both population growth and

\footnotetext{
* Correspondence: mick.watson@roslin.ed.ac.uk

The Roslin Institute and R(D)SVS, University of Edinburgh, Easter Bush Midlothian EH25 9RG, UK
}

increased affluence in low- and middle-income countries (LMICs). Terrestrial and aquatic animal production in these countries is heavily reliant on small-holder farmers, who collectively play a crucial role in global animal protein production. For example, of the 570 million farms worldwide, over 1 in 4 (150 million) have at least one milk-producing animal [4], and farms with fewer than 100 animals account for over $99.7 \%$ of global dairy production [5]. In LMICs, livestock accounts for over $60 \%$ of agricultural gross domestic product (GDP) [6], and farmed animals provide livelihoods for over 1 billion people globally [7]. While increasing reliance on plant-based diets is often raised as a potential solution to food insecurity and as part of the effort required to address climate change [8], omission of animal protein from human diets risks nutritional deficiencies and malnutrition [9]. There are also large geographical regions where livestock represent the most feasible land-use option, such as the dry lands that cover $60 \%$ of SubSaharan Africa [10].

In 2011, Sir John Beddington led a team of experts who examined the intricate links between global demand for food, energy and water. When placed within the context of climate change, he described the concurrent and rapid increase in demand for these commodities as "a perfect storm" [11]. The subsequent FORESIGHT report [12] identified six key pressures on global food production systems that already fail to feed the human population - global population increase, changes in consumer demand, changes in local and global governance, climate change, competition for key resources (e.g. clean water), and changes in the ethical stance of consumers. The goal of producing more food whilst using fewer resources is a major challenge for our species.

Here, we review the impact of genomics, transgenesis and genome editing on issues that influence farm-animal productivity, health and welfare, and on 
our ability to produce food, and go on to discuss the potential future impact of transgenic and genomeediting technologies (Fig. 1).

\section{The impact of genetic improvement on animal production}

While many farmed animals have undergone the process of domestication for millennia, managed selective breeding programs have resulted in striking improvements in productivity. Genetic improvement has resulted in faster, cheaper, healthier, and more-efficient animal production, with reduced impact on the environment. For example, from the 1960 s to 2005 , selective breeding resulted in $50 \%$ larger litter sizes in pigs, an increase of lean pork meat of $37 \%$, and a doubling of lean pork meat per $\mathrm{kg}$ of feed intake; in chickens, the days to acquire $2 \mathrm{~kg}$ of mass reduced from 100 days to 40 , the percentage breast meat increased from 12 to $20 \%$, the feed conversion ratio halved, eggs per year increased by $30 \%$ and eggs per tonne of feed increased by $80 \%$; and finally, in cattle, milk production increased by $67 \%$ [13]. These transformative increases in food production represent incredible achievements in just a few decades, albeit the benefits were disproportionately seen in developed countries.

Pedigree-based breeding programmes for major livestock and aquaculture species now routinely incorporate genomic selection, which has been a revolutionary change for selective breeding and food production.
Genomic selection [14, 15] involves the use of genome-wide genetic marker data to estimate genomic breeding values (GEBVs) of individuals by means of a genomic prediction equation. This genomic prediction equation is calculated using a 'training' or 'reference' population where animals have both genotypes and phenotypes, and is then applied to selection candidates, which often have marker genotype information only. The rates of genetic gain have been estimated to lie between 20 and $30 \%$ in cattle, pigs, chickens and salmon [16].

Genomic improvements have been accelerated by community-driven pre-competitive research in animal genomics and functional genomics. The major farmanimal genomes have been sequenced [17-19], with efforts under way to functionally annotate these genomes to the same standard as the human genome [20-22]. Some farm-animal genomes now represent the most contiguous complex genomes ever sequenced [23, 24]. Built on these efforts, genomic tools [25-30] and new and cheaper sequencing technologies [31,32] have been, or will be, major contributors to modern animal breeding and the improved productivity of farmed animals.

Selective breeding is constrained by the standing genetic variation in the species or population of interest, and new variants arising through de novo mutations. Transgenic and genome-editing technologies offer new opportunities for genetic improvement by creating novel beneficial alleles or introducing known desirable alleles from other breeds or species, without the consequences

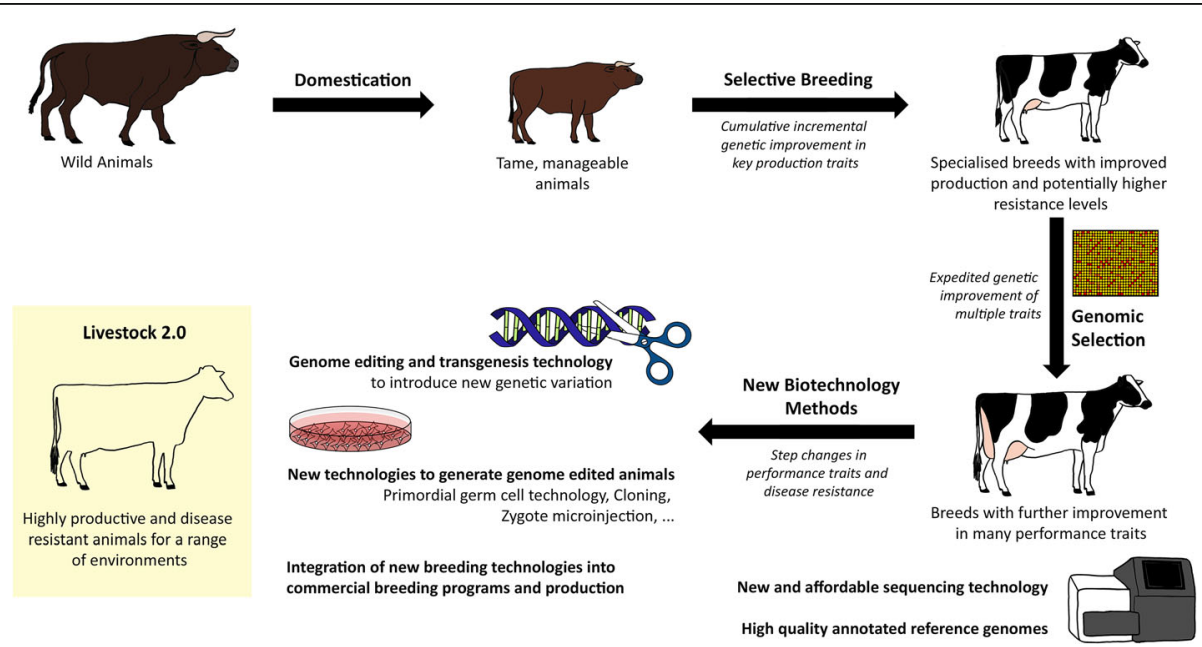

Fig. 1 Pathways to 'Livestock 2.0'. A brief summary of the developments in livestock breeding and what new technologies might offer to the industry. Selective breeding and genomic selection have already improved productivity and disease resistance in livestock significantly. Genome editing and transgenesis could facilitate step improvements through (i) rapidly increasing the frequency of favorable trait-associated alleles, (ii) introgression of favorable alleles from other breeds/species without linkage drag, and (iii) creation of de novo favorable alleles. A key challenge will be the identification of genome-editing targets, which will require a combination of high-quality annotated livestock genomes, well-powered genome-wide association studies, reverse-genetic screens (e.g. genome-wide CRISPR knock-out), and high-resolution knowledge of the biology of the target traits. CRISPR, clustered regularly interspaced short palindromic repeat 
of the linkage drag associated with traditional introgression. Below, we summarize some of the applications of both genetic modification and genome editing to farm-animal productivity and health.

\section{Examples of genetic modification}

Genetic modification of farmed animals to increase the efficiency of food production, increase animal health and welfare, yet reduce the environmental footprint, has been a goal for many decades (Table 1). Early work focused on attempts to increase growth. Muscle development and body mass are controlled at a high level through the pituitary gland and liver, through the growth hormone-insulin-like growth factor axis (GH-GF axis) [33]. Growth hormone (GH) is released by the pituitary gland and stimulates the expression of insulin-like growth factor 1 (IGF1) in all tissues, including muscle. The predominant source of systemic IGF1 is the liver, and both muscle- and liver-derived IGF1 have been found to stimulate muscle hypertrophy. IGF2, a sister molecule of IGF1, has key roles in myogenesis [33], and mutations in a regulatory region of the IGF2 gene are associated with an increased level of muscle growth in pigs [34]. Pursel and colleagues [35] successfully introduced genes encoding two growth-related hormones $(\mathrm{GH}$ and IGF-1) into pigs by DNA microinjection into zygotes. Two lines of pigs expressing the transgene encoding $\mathrm{GH}$ gained mass 11.1 and $13.7 \%$ faster than control pigs, and were demonstrated to have $18 \%$ more efficient feed conversion. The mechanism appeared to operate through resource diversion, with lower levels of subcutaneous fat, and increased development of muscle, skin and bone [35]. A subsequent study [36] focused only on IGF-1, with transgenic pigs having significantly less fat and significantly more lean tissue (albeit with growth rates similar to those of control pigs). Although pigs from the latter study had no health issues, the GH transgenic pigs suffered increased lameness, lethargy and gastric ulcers and possessed a lower ability to respond effectively to stress [37]. These deleterious characteristics led to the cessation of this project.

A similar approach was taken in farmed salmon, which were genetically modified to produce a rapid-growth phenotype. The AquAdvantage salmon strain (AquaBounty Technologies Inc., MA, USA) shows improved growth relative to wild-type salmon (in specialized onshore production systems) owing to the integration of a growth hormone gene from a Chinook salmon (Oncorhynchus tshawytscha) together with a promoter from ocean pout (Macrozoarces americanus), a cold-water ray-finned fish, to drive increased expression of growth hormone. A landmark in the field of genetically modified (GM) food animals was the approval of this GM salmon strain as fit for human consumption by the US Food and Drug Administration and the Canadian Food Inspection Agency in 2017. The approval of this product for sale represents the first genetically engineered animal to be sold on the open market, and took approximately 25 years to reach this stage [38].

Transgenic technology, in some cases combined with genome editing, allows for the introduction of new properties to animal protein that could have potential benefits for the human diet. For example, Lai and colleagues generated cloned pigs that expressed the fat-1 gene from the nematode Caenorhabditis elegans and that exhibited significantly reduced ratios of n- 6 to $n-3$ fatty acids, which might have human health benefits [39]. Although some have questioned the value of such pigs [40], nevertheless others have also generated pigs carrying the $C$. elegans fat-1 gene (which encodes an n-3 fatty acid desaturase) and have observed similar changes [41, 42], including $\mathrm{Li}$ and colleagues, who used 'clustered regularly interspaced short palindromic repeats' (CRISPR)-CRISPR-associated 9 (Cas9) gene-editing technology for the

Table 1 Examples of transgenesis for disease resilience and other production traits

\begin{tabular}{|c|c|c|c|}
\hline \multicolumn{4}{|l|}{ Genetic modification/transgenesis } \\
\hline Trait & Species & Transgene & Reference(s) \\
\hline \multirow[t]{2}{*}{ Increased growth } & Pig & Growth hormone (GH) and insulin-like growth factor 1 (IGF-1) & {$[35-37]$} \\
\hline & Salmon & GH (Chinook salmon), promoter (Ocean pout) & [38] \\
\hline Larger ratio of $n-3$ to $n-6$ fatty acids & Pig & Fat-1 (Caenorhabditis elegans) & [39-43] \\
\hline \multirow{2}{*}{$\begin{array}{l}\text { Reduction of the environmental impact through } \\
\text { phosphorous \& nitrogen release reduction }\end{array}$} & \multirow[t]{2}{*}{ Pig } & Phytase (Escherichia coli) & [44] \\
\hline & & $\begin{array}{l}\text { Phytase (E. coli), xylanase (Aspergillus niger), } \beta \text {-glucanase } \\
\text { (Bacillus lichenformis) }\end{array}$ & [45] \\
\hline Avian influenza resilience & Chicken & shRNA decoy (synthetic) & [48] \\
\hline \multirow[t]{2}{*}{ Mastitis resilience } & Goat & Lysozyme (human) & [50] \\
\hline & Cow & Lysostaphin (Staphylococcus simulans) & [52] \\
\hline PRRSV resilience & Pig & Histone deacetylase HDAC6 & {$[67,94]$} \\
\hline
\end{tabular}

Abbreviations: GH growth hormone, PRRSV porcine reproductive and respiratory syndrome virus, sh short hairpin 
directed integration of the fat-1 gene from C. elegans into the porcine Rosa 26 locus [43].

Several groups have attempted to reduce the environmental impact of pig production through the addition of microbial genes into the pig genome [44, 45]. Dietary supplementation with phosphate and nitrogen is required to achieve optimal growth in many farm-animal species. Although phosphate, in the form of plant phytate, is present in their usual diet, farm animals are unable to digest it. The incompletely digested phosphorous and nitrogen are released into the environment through evaporation, manure and runoff and can disrupt local ecosystems. Golovan and colleagues [44] produced transgenic pigs that express an Escherichia coli-derived phytase gene, resulting in almost 100\% digestion of dietary phytate, removing the need for phosphate supplementation. In a more recent effort, Zhang and collaborators [45] addressed the inefficient digestion of both phosphorous and nitrogen in pigs by generating transgenic pigs that not only expressed the microbial phytase enzyme but also xylanase and $\beta$-glucanase. This not only increased the growth rate of pigs by 23 and $24.4 \%$ in females and males, respectively, but also resulted in a reduction of fecal nitrogen and phosphorous by up to $45.8 \%$.

Increased resistance to disease has been a goal of both selective breeding and genome engineering for many years. Avian influenza is an ongoing threat to poultry production world-wide, the economic impacts of major avian influenza outbreaks are very high [46] and the potential for development of human pandemic influenza infections is a continuing significant risk [47]. Avian influenza in production poultry can be controlled by vaccination or high biosecurity, but effective vaccines have yet to be developed, and high biosecurity cannot realistically be implemented by smallholder farmers. The potential of a novel alternative strategy - introduction of a transgene that would confer resistance to avian influenza - was tested by Lyall and colleagues [48]. Transgenic chickens were developed that expressed a short-hairpin RNA, based on the design described by Luo and colleagues [49]. This RNA molecule was designed to act as a decoy that blocks avian influenza virus polymerase, consequently inhibiting viral propagation. These transgenic birds were challenged with highly pathogenic avian influenza virus, and, although the birds succumbed to the initial challenge, transmission of the infection to transgenic and control birds was prevented.

Research has also focused on attempting to control mastitis using transgenic technology. Mastitis is one of the most common diseases of dairy cattle and has a huge negative impact on the industry, resulting in estimated annual losses of $\$ 2 \mathrm{bn}$. The most common causative agent of persistent mastitis is Staphylococcus aureus, and resilience to this pathogen has a low natural heritability.
Therefore, research has focused on transgenic strategies to create animals that express enzymes that inhibit the growth of mastitis-causing pathogens. Goats expressing human lysozyme have been shown to inhibit mastitiscausing bacterial growth $[50,51]$, whilst at the same time having little to no effect on the beneficial bacterium Lactococcus lactis, required for making dairy products such as cheese. Furthermore, transgenic cattle have been produced that express the antibiotic lysostaphin [introduced by somatic cell nuclear transfer (SCNT)] in their milk, which can prevent infection by $S$. aureus [52].

The above examples of transgenic animals generally predate the advent of genome-editing technologies. Genome editing by zinc-finger nucleases (ZFNs), transcription activator-like effector nucleases (TALENs), and CRISPR-Cas9 (and related enzymes) is known to be more accurate and efficient than transgenesis. Below we provide examples of early successes of the technology in farmed animals.

\section{Examples of genome editing}

Compared with genetic modification, which relies on the incorporation of transgenes to enhance traits in livestock, genome editing offers an opportunity to make specific and precise changes to the genome of an animal to increase productivity and disease resistance. The myostatin gene (MSTN) is a common target for research into increased growth and muscle development. First identified in heavily muscled cattle and sheep breeds, such as Belgian Blue and Piedmontese cattle and the Texel sheep breed, it was found that an underactive gene for myostatin (also known as growth differentiation factor 8 , GDF8) results in increased muscle growth. The underlying genetic variations are changes in the myostatin gene directly - an 11-bp deletion in the Belgian blue and a single-nucleotide polymorphism in the Piedmontese [53, 54]. Interestingly, the Texel breed encodes a regulatory mutation in the myostatin gene untranslated region (UTR), creating a target site enabling downregulation of the myostatin mRNA by two microRNAs [55]. Thus, the myostatin gene was an obvious early target for gene editing in farmed animal species as disruption of this single gene has significant effects on a trait of economic importance. To date, the farmed animals in which the myostatin gene has been edited include cattle [56], sheep [56, 57], goat [58] and Channel Catfish [59] (Table 2). The pig myostatin gene, however, has been the most frequently targeted [60-66] - perhaps as pork is the leading global source of meat by weight, or perhaps because of the lack of natural disruptive mutations detected in this gene to date. The first report by Ning $\mathrm{Li}$ and colleagues at the 10th World Congress on Genetics Applied to Livestock Production [67] reported problems in the pigs that were homozygous for a myostatin 
Table 2 Examples of genome editing for disease resistance and other production traits

\begin{tabular}{|c|c|c|c|}
\hline \multicolumn{4}{|l|}{ Genome editing } \\
\hline Trait & Species & Genome-editing target & Reference(s) \\
\hline \multirow[t]{5}{*}{ Increased muscle growth (double-muscle phenotype) } & Cow & Myostatin (GDF8) & {$[56]$} \\
\hline & Sheep & Myostatin (GDF8) & {$[56,57]$} \\
\hline & Goat & Myostatin (GDF8) & {$[58]$} \\
\hline & Channel Catfish & Myostatin (GDF8) & {$[59]$} \\
\hline & Pig & Myostatin (GDF8) & {$[60-66]$} \\
\hline Hornlessness (Polled) & Cow & PC POLLED & {$[74]$} \\
\hline $\begin{array}{l}\text { Boretaint (Hormone release during sexual maturity } \\
\text { leading to undesired meat taste) }\end{array}$ & Pig & KISS1R & {$[75]$} \\
\hline Sterility & Salmon & Dead end protein (dnd) & {$[78]$} \\
\hline \multirow[t]{2}{*}{ Sterility/surrogate hosts } & Pig & Nanos2 & {$[79]$} \\
\hline & Chicken & DDX4 (Vasa) & {$[80]$} \\
\hline PRRSV resistance & Pig & CD163 & [90-93] \\
\hline ASFV resilience & Pig & RELA & {$[95,96]$} \\
\hline Mannheimia (Pasteurella) haemolytica resilience & Cow & CD18 & {$[97]$} \\
\hline Bovine tuberculosis resilience & Cow & NRAMP1 & {$[99]$} \\
\hline Xenotransplantation (removal of endogenous retroviruses) & Pig & Porcine endogenous retrovirus genes & {$[106,107]$} \\
\hline
\end{tabular}

Abbreviations: ASFV African swine fever virus, GDF growth and differentiation factor, PRRSV porcine reproductive and respiratory syndrome virus

knockout, including the development of abnormal legs, an inability to stand and walk, and death. Similarly, mutations in myostatin have recently been associated with a recessive leg weakness syndrome in pigs [68]. Although Kang et al. [60] reported hypermuscling, increased lean, and reduced backfat in pigs with gene-edited knockouts of the myostatin gene, they also reported some health issues in the homozygous knockout pigs, and homozygous myostatin knockout Landrace piglets died only a few days after birth [65]. More recently, Wang et al. disrupted the myostatin gene in Erhualian pigs [61] and observed some double-muscle associated phenotypes. Although no health issues were reported, further characterization of the edited animals is required. Erhualian and Meishan pigs are two Chinese breeds known for high fat levels, and edited pigs with disrupted myostatin genes on these genetic backgrounds appear to fare better than those on leaner genetic backgrounds [61, 62].

Beyond growth phenotypes, there has been a focus on more-efficient farming practices and animal and human welfare. Physical dehorning has many benefits to cattle, their handlers and the farming industry, including reduced risk of injury, reduced competition for feedingtrough space, and fewer aggressive behaviors [69]. It has been estimated that $80 \%$ of dairy farmers in Italy [70] and $93 \%$ [71] of dairy farmers in the USA practice routine dehorning of dairy cattle. Despite the benefits, dehorning of dairy cattle represents an animal-welfare concern, owing to the pain caused and potential for injury. Naturally hornless cattle (termed 'polled') do exist and are far more prevalent in beef cattle than in dairy. The genetic cause of polled cattle has been the subject of intense genetic research, resulting in the suggestion that one of two alleles must be causal [72, 73]. Carlson and colleagues [74] used TALEN to introduce the Pc POLLED allele into the genome of bovine embryo fibroblasts from four lines of cattle. These were cloned using somatic-cell transfer, resulting in full-term pregnancies for three of the four lines. Five live calves were produced; however, only two were viable and went on to survive to day 60 (at the time of publication). All five calves were determined to have a likely polled phenotype at birth, and the two surviving calves were confirmed to be polled. Not only does this confirm the causality of the Pc POLLED allele, but it also represents a potential approach for reducing physical dehorning in dairy cattle without a loss of productivity.

Surgical castration of pigs is a common practice in pork production to reduce aggressive behaviour and to avoid the accumulation of androstenone and skatole, which leads to the boar taint taste and odor of non-castrated male pork. Sonstegard and colleagues generated pigs with a knock-out of the KISS1R gene, encoding a receptor responsible for the onset of puberty in vertebrates and involved in the regulation of gonadotropin-releasing hormone [75]. The knock-out pigs showed a lack of testicular development but reacted to hormone treatment, which increased testicular size. However, it remains to be tested whether the animals can become fertile and whether growth properties are affected. Genome-wide association 
studies (GWAS) further highlight that the boar taint components and testicular trait regions have pleiotropic effects, which might impact the applicability of genetic interventions for this trait $[76,77]$.

Sterility has also been a focus in farmed Atlantic salmon, with a view to avoid escapees interbreeding with wild stocks. Genome-editing approaches have also been successfully applied [78], with the initial target being the dead end protein (encoded by the $d n d$ gene) in order to induce sterility.

Research has also focused on methods to integrate genome-editing technologies into existing genomicselection strategies. For example, a major barrier to the adoption of genomic selection in some areas has been the reliance on techniques such as artificial insemination of high-value germplasm, which relies on skills and infrastructure that are not accessible in all parts of the world. One solution is to generate sterile host animals that can be used to distribute transplanted high-value germplasm. Specific gene ablation of loci important for germ-cell development can generate animals that lack endogenous germ cells in homozygous individuals. Animals can then be distributed that will carry high-quality transplanted germplasm to geographic regions that are not serviced by the infrastructure needed for cryopreserved semen distribution. Both sterile pigs and sterile chickens have been produced using genome-editing technologies $[79,80]$. Sterile surrogate hosts for poultry are especially valuable as cryopreservation methods in poultry are lacking. All poultry flocks are kept as breeding populations as it is impossible to freeze the chicken egg, and cryopreservation of chicken semen is inefficient and breed specific [81]. The early diploid germ cells of poultry can be cryopreserved and form functional gametes when transplanted into surrogate host chickens [82]. When transplanted into sterile surrogate chickens, it is now possible to reconstitute pure poultry flocks from frozen material $[83,84]$.

Finally, as with transgenesis, many groups focus their research on the potential of genome editing for control of infectious diseases (Table 2). Here there are clear opportunities, especially in cases where conventional control options have shown limited success. The development of pigs resistant to porcine reproductive and respiratory syndrome virus (PRRSV) exemplifies this strategy. PRRS is arguably the most important infectious disease problem for the pig industry worldwide. The losses from PRRS are estimated at $\$ 2.5$ billion per annum in the USA and Europe alone. Quantitative genetics studies have identified substantial genetic variation in the resistance and tolerance of pigs to PRRS $[85,86]$, with a single locus on pig chromosome 4 (GBP5, encoding guanylate-binding protein 5) explaining $15 \%$ of the total genetic variation in viral load and $11 \%$ of genetic variation for growth rate in pigs infected with PRRSV $[87,88]$. Although these results could offer promising opportunities for mitigating PRRS through genomic selection, predicting the impact of genomic selection on PRRS prevalence is difficult as the role of the GBP5 locus in PRRS transmission is currently not known. In vitro research has shown that the macrophage surface protein CD163 and specifically the scavenger receptor cysteine-rich domain 5 (SRCR5) of the CD163 protein mediate entry of PRRSV into the host cell [89]. Based on this information, genome-edited pigs could be generated with a disruption to the $C D 163$ gene, giving rise to resistance to PRRSV infection. Whitsworth and colleagues knocked-out the CD163 gene completely by the introduction of a premature stop codon by means of non-homologous end-joining events in exon 7 [90, 91]. A subtler approach by Burkard et al. removed only the SRCR5-encoding genome section, a deletion of exon 7, thus maintaining the expression and biological function of the $C D 163$ gene $[92,93]$. Both approaches resulted in resistance to PRRSV infection [90-93], in contrast to the partial resistance conferred by the GBP5 genotype in existing pig populations. Transgenic strategies to enhance resistance to PRRSV infection have also been attempted, including overexpression of histone deacetylase 6 (HDAC6), with the resulting transgenic pigs showing lower viral load and longer survival [67, 94]. However, such studies do not deliver the complete resistance observed in the pigs in which the endogenous CD163 gene has been edited.

African swine fever (ASF) is another hugely important disease of pigs. Caused by African swine fever virus (ASFV), ASF is a disease endemic to huge swathes of sub-Saharan Africa, which has recently been introduced to Eastern Europe, from where it is rapidly spreading to Western Europe as well as China. Native suid hosts, including the warthog, are resilient to the infection, whereas domestic pigs develop a lethal haemorrhagic fever mainly caused by a cytokine storm in the host. Variation in the RELA gene between resilient and susceptible suidae has been postulated to underlie this phenotype [95]. RELA is a component of the NF- $k B$ transcription factor, known to play a role in stress and immune responses. Using a ZFN, researchers were able to convert the domestic pig protein sequence for RELA to that of the warthog [96] - however, data to show resilience to ASFV have yet to be reported.

Genome editing offers the potential for control of several other diseases. Mannheimia (Pasteurella) haemolytica infection causes epizootic pneumonia (shipping fever), enzootic pneumonia and peritonitis in calves, lambs and sheep. $M$. haemolytica produces a leukotoxin that is cytotoxic and that binds to the uncleaved signal peptide of the CD18 protein on the surface of leukocytes. 
However, in other species that do suffer disease (e.g. mouse and human), the mature CD18 lacks the signal peptide. ZFNs have been used to introduce a single amino acid change in the cattle CD18 protein, and leukocytes from the resultant fetuses were resistant to $M$. haemolytica leukotoxin-induced cytotoxicity [97]. Bovine tuberculosis (bTb) is a potential zoonotic that has a huge and negative impact on productivity in cattle and buffalo. Polymorphisms in the NRAMP1 gene in cattle have been associated with resilience to $\mathrm{bTb}$ [98]. Insertion of the resilient NRAMP1 allele into cattle using CRISPR-Cas9 has been performed by Gao et al. [99]. Peripheral blood monocytes challenged with Mycobacterium bovis showed reduced pathogen growth, and an in vivo study using the edited animals reported a diminished interferon response.

The success of gene-edited animals in disease control will be influenced by many factors - for example, the proportion of gene-edited animals in the population and how these are distributed within and across farms. According to epidemiological theory, only a proportion of gene-edited animals would suffice to achieve herd immunity - that is, prevent disease from spreading within local populations [100]. Improved, disease-specific epidemiological models can help define the exact proportion of gene-edited animals needed for each species/ disease, influenced by population structure, demographic characteristics, diverse environmental factors and management strategies influencing transmission dynamics, and the effectiveness of genome editing.

A common aspect of disease mitigation strategies is that of limited shelf-life. Genome editing shares the potential risk of vaccines in that its efficacy might be time limited owing to emergence of escape mutants [101]. For an RNA virus such as PRRSV with extremely high mutation rates [102], this seems a justified concern. Hence the question is not only "how many gene-edited pigs do we need to control disease?", but also "how fast can these be realistically disseminated?"

It is important to differentiate between disease resistance, the ability of an animal to suppress the establishment and/or development of an infection, and disease resilience, where an infected host manages to maintain an acceptable level of productivity despite challenge pressure. For example, in the case of African swine fever, genome editing might primarily boost the tolerance of pigs to infection, rather than their resistance to becoming infected. Although genetic improvement of tolerance is considered to impose less risk for pathogen evolution towards higher virulence than genetic improvement of resistance, genetically tolerant individuals do not stop disease from spreading. In fact, the presence of genetically tolerant individuals that do not develop symptoms when infected, within a mixed population, might enhance disease incidence and prevalence.
Although not related to food production, a fascinating potential use of livestock is in the production of organs for human transplantation. Here also genome editing has a role. Xenotransplantation describes the process of transplanting an organ from one species into another and has become a hot topic of research owing to the lack of suitable human donors [103]. Pigs have been a natural focus of xenotransplantation research owing to their similarity in physiology and size - however, there are concerns over the risk of retroviral transmission from pig to human $[104,105]$. Porcine endogenous retroviruses (PERVs) are retroviruses found within the genome of all pigs. As they are integrated into the genome, they exist in all tissues and organs and are passed on by inheritance. Genome editing is one possible avenue for removing or inactivating PERVs within pig genomes, thus making their organs suitable for xenotransplantation. Yang and colleagues [106] demonstrated this first, inactivating all 62 PERVs within the genome of a pig cell line (PK15) and reducing the levels of transmission to human cells by over 1000 fold. A follow-up study by Niu et al. [107] generated PERV-inactivated pigs through SCNT, having inactivated all the PERVs in a porcine primary cell line using CRISPR-Cas9. Genomic and transcriptomic analysis of the resulting pigs suggested $100 \%$ elimination of PERV activity.

\section{Discussion and future outlook}

For many years genetics/genomics and selective breeding have had a transformative impact on livestock production and health, producing huge gains for the breeding industry, farmers and consumers. Underpinned by genomic tools and reference datasets, genomic selection has been (or is being) adopted worldwide to deliver consistent, predictable improvements in multiple species and farming systems. While selective breeding has resulted in successful incremental improvements in target traits, it typically relies on naturally occurring genetic variation within a population.

Transgenic and genome-editing technologies offer the opportunity for larger gains over a shorter time-period and can call on variation present in other populations and species, variation in non-domesticated species, and novel alleles designed to be beneficial. Resilience to ASFV is a potential example whereby an allele only present in the wild warthog population, which has co-evolved with the pathogen for many thousands of years, has been introduced into domesticated pigs by genome editing. Although we do not know the phenotype of the edited pigs, the concept of introducing beneficial alleles from a wild population into domesticated equivalents is sound. The allele conferring resistance to PRRSV introduced by Burkard and colleagues is an example of a 'designer allele' - the researchers knocked 
out a single exon of the CD163 gene, thought to be involved in interactions with the virus, and this simple edit appears to have produced resistant pigs that maintain normal CD163 functionality. To our knowledge, pigs lacking this exon have never been seen in any population, and therefore equivalent pigs would be impossible to produce by either artificial or natural selection. Elimination of this devastating disease of pigs could now be possible through the use of genome-edited pigs.

The older transgenic technologies have been applied to livestock since the 1990s, and there are many examples in this review - but why have so few engineered animals actually made it to market? For transgenic animals, the answer might come from the only success story, the AquAdvantage salmon. This product took 25 years to reach the market, with the first application for FDA approval occurring in 1995 [108]. Clearly, a more rapid approach to regulatory clearance is needed if more transgenic products are to hit the market and provide advantages to consumers, farmers, and breeders alike.

It is clear that precise, accurate genome-editing techniques are very different in nature to transgenesis. The legal regulatory paths for genome-edited animals have yet to be established, and all of the examples covered herein are at a very early stage. However, huge strides have been made, and in particular the PRRS-resistant pigs produced at Missouri and Roslin offer great potential to eradicate or minimize this devastating disease. Effectively removing PRRS from pig farms would benefit farmers, consumers, and the pigs themselves. Other examples are not far behind, and, if much-hoped-for progressive regulatory pathways are established, then the effects on livestock production could be huge.

The examples described above naturally involve single alleles of large effect that are amenable to genome editing. Beyond these simple examples, many traits of interest are complex - that is, they are governed by many alleles, each of small effect. To achieve significant impact from genome editing by harnessing existing genetic variation for a complex trait, one would need to edit multiple alleles simultaneously, and editing approaches would need to be routinely integrated within commercial breeding-programme operations. Simulations have shown that, even with complex traits, genome editing could have a role in livestock improvement, either by increasing the frequency of favorable alleles [109] or removing deleterious alleles [110] as part of a genomicselection-driven breeding programme.

Assuming that the regulatory pathways can be defined, and considering that genome editing is precise and quick, there must now be a renewed focus on the identification of editing targets. In the examples above, the identification of the target genes has come from a wide variety of approaches encompassing genetics, genomics, large-scale
CRISPR-based functional screens, host-pathogen interactions, virology, bacteriology and serendipity. Although the latter cannot be planned for, it is clear that all of the other approaches, within an integrated, co-ordinated international programme of research, have the potential to identify targets that can provide huge benefits to the livestock sector and will have a transformational impact on the ability of our species to produce sufficient food in an environmentally sustainable way.

\section{Abbreviations \\ ASF: African swine fever; ASFV: African swine fever virus; bTb: Bovine tuberculosis; CRISPR: Clustered regularly interspaced short palindromic repeat; FAO: Food and Agriculture Organization of the United Nations; GM: Genetically modified; LMIC: Lower- and middle-income country; PERV: Porcine endogenous retrovirus; PRRS: Porcine reproductive and respiratory syndrome; PRRSV: Porcine reproductive and respiratory syndrome virus; TALEN: Transcription activator-like effector nuclease; UTR: Untranslated region; ZFN: Zinc-finger nuclease}

\section{Funding}

The Roslin Institute forms part of the Royal (Dick) School of Veterinary Studies, University of Edinburgh. This project was supported by the Biotechnology and Biological Sciences Research Council (BB/R004463/1), including institute strategic programme and national capability awards to The Roslin Institute (BB/P013732/1, BB/P013740/1, BB/P013759/1).

\section{Authors' contributions}

MW and CBW conceived of the review. CTB, ADW, MM, ALA, HMS, RDH, CBW and $\mathrm{MW}$ all contributed to the text and structure of the review and the response to the reviewers. CTB produced Fig. 1. All authors read and approved the final manuscript.

\section{Competing interests}

The authors declare that they have no competing interests.

\section{Publisher's Note}

Springer Nature remains neutral with regard to jurisdictional claims in published maps and institutional affiliations.

Published online: 26 November 2018

References

1. 2018 - Hunger Map. World food program. United Nations world food Programme - fighting hunger worldwide. 2018. https://www.wfp.org/ content/2018-hunger-map. Accessed 30 Oct 2018.

2. United Nations. World population Prospects 2015. https://population.un.org/ wpp/Publications/Files/Key_Findings_WPP_2015.pdf. Accessed 30 Oct 2018.

3. Alexandratos N, Bruinsma J. World agriculture towards 2030/2050: the 2012 revision. 2030. http://www.fao.org/fileadmin/templates/esa/Global_ persepctives/world_ag_2030_50_2012_rev.pdf. Accessed 30 Oct 2018.

4. Lowder SK, Skoet J, Raney T. The number, size, and distribution of farms, smallholder farms, and family farms worldwide. World Dev. 2016;87:16-29 https://doi.org/10.1016/j.worlddev.2015.10.041

5. FAO. The Global Dairy Sector: Facts. https://www.fil-idf.org/wp-content/ uploads/2016/12/FAO-Global-Facts-1.pdf. Accessed 30 Oct 2018.

6. FAO. Livestock's long shadow. 2006. http://www.fao.org/docrep/010/ a0701e/a0701e00.HTM. Accessed 30 Oct 2018.

7. Global Agenda for Sustainable Livestock. Towards sustainable livestock. Livestock in development. 2014. http://www.livestockdialogue.org/ fileadmin/templates/res_livestock/docs/2014_Colombia/2014_Towards_ Sustainable_Livestock-dec.pdf. Accessed 30 Oct 2018.

8. IPCC - SR15. http://www.ipcc.ch/report/sr15/. Accessed 30 Oct 2018.

9. White RR, Hall MB. Nutritional and greenhouse gas impacts of removing animals from US agriculture. Proc Natl Acad Sci U S A. 2017;114:E10301-8.

10. De Haan C, Dubern E, Garancher B, Quintero C. Fragility, conflict, and violence. Cross-cutting solutions area. A road to stability? Pastoralism development in the Sahel. 2016. http://documents.worldbank.org/curated/ 
en/586291468193771160/pdf/105197-WP-PUBLIC-PUBDATE-5-16-2016.pdf. Accessed 30 Oct 2018

11. Beddington J. Food, energy, water and the climate: a perfect storm of global events? http://webarchive.nationalarchives.gov.uk/20121206120858/ http://www.bis.gov.uk/assets/goscience/docs/p/perfect-storm-paper.pdf. Accessed 30 Oct 2018

12. Government Office For Science. The future of food and farming: challenges and choices for global sustainability. https://www.gov.uk/ government/uploads/system/uploads/attachment_data/file/288329/11546-future-of-food-and-farming-report.pdf. Accessed 30 Oct 2018.

13. van der Steen HAM, Prall GFW, Plastow GS. Application of genomics to the pork industry. J Anim Sci. 2004;83:E1-8 https://academic.oup.com/jas/articleabstract/83/suppl_13/E1/4790535.

14. Meuwissen TH, Hayes BJ, Goddard ME. Prediction of total genetic value using genome-wide dense marker maps. Genetics. 2001;157:1819-29.

15. Haley CS, Visscher PM. Strategies to utilize marker-quantitative trait loci associations. J Dairy Sci. 1998;81:85-97 https://doi.org/10.3168/jds.S00220302(98)70157-2.

16. Meuwissen T, Hayes B, Goddard M. Accelerating improvement of livestock with genomic selection. Annu Rev Anim Biosci. 2013;1:221-37.

17. Hillier LW, Miller W, Birney E, Warren W, Hardison RC, Ponting CP, et al. Sequence and comparative analysis of the chicken genome provide unique perspectives on vertebrate evolution. Nature. 2004;432:695-716 http://www. nature.com/doifinder/10.1038/nature03154.

18. Groenen MAM, Archibald AL, Uenishi H, Tuggle CK, Takeuchi Y, Rothschild MF, et al. Analyses of pig genomes provide insight into porcine demography and evolution. Nature. 2012;491:393-8 http://www.nature.com/doifinder/10.1038/ nature11622.

19. Bovine Genome Sequencing and Analysis Consortium, Elsik CG, Tellam RL, Worley KC, Gibbs RA, Muzny DM, et al. The genome sequence of taurine cattle: a window to ruminant biology and evolution. Science. 2009:324:522-8 http://science.sciencemag.org/content/324/5926/522.

20. Andersson L, Archibald AL, Bottema CD, Brauning R, Burgess SC, Burt DW, et al. Coordinated international action to accelerate genome-to-phenome with FAANG, the functional annotation of animal genomes project. Genome Biol. 2015:16:57 http://genomebiology.com/2015/16/1/57.

21. Macqueen DJ, Primmer CR, Houston RD, Nowak BF, Bernatchez $L$, Bergseth $\mathrm{S}$, et al. Functional annotation of all salmonid genomes (FAASG): an international initiative supporting future salmonid research, conservation and aquaculture. BMC Genomics. 2017;18:484 http:// bmcgenomics.biomedcentral.com/articles/10.1186/s12864-017-3862-8.

22. Tuggle CK, Giuffra E, White SN, Clarke L, Zhou H, Ross PJ, et al. GO-FAANG meeting: a gathering on functional annotation of animal genomes. Anim Genet. 2016;47:528-33 https://doi.org/10.1111/age.12466.

23. Bickhart DM, Rosen BD, Koren $S$, Sayre BL, Hastie AR, Chan S, et al. Single-molecule sequencing and chromatin conformation capture enable de novo reference assembly of the domestic goat genome. Nat Genet. 2017;49:643-50 http://www.nature.com/doifinder/10.1038/ng.3802.

24. Sus scrofa 11.1 [https://www.ncbi.nlm.nih.gov/genome/84]. Accessed 30 Oct 2018

25. Kranis A, Gheyas AA, Boschiero C, Turner F, Yu L, Smith S, et al. Development of a high density 600K SNP genotyping array for chicken. BMC Genomics. 2013:14:59.

26. Houston RD, Taggart JB, Cézard T, Bekaert M, Lowe NR, Downing A, et al. Development and validation of a high density SNP genotyping array for Atlantic salmon (Salmo salar). BMC Genomics. 2014;15:90.

27. Freeman TC, Ivens A, Baillie JK, Beraldi D, Barnett MW, Dorward D, et al. A gene expression atlas of the domestic pig. BMC Biol. 2012;10:90.

28. Robert C, Fuentes-Utrilla P, Troup K, Loecherbach J, Turner F, Talbot R, et al. Design and development of exome capture sequencing for the domestic pig (Sus scrofa). BMC Genomics. 2014;15:550.

29. Clark EL, Bush SJ, McCulloch MEB, Farquhar IL, Young R, Lefevre L, et al. A high resolution atlas of gene expression in the domestic sheep (Ovis aries). PLoS Genet. 2017; https://doi.org/10.1371/journal.pgen.100699713(9):e1006997.

30. Ramos AM, Crooijmans RPMA, Affara NA, Amaral AJ, Archibald AL, Beever JE, et al. Design of a high density SNP genotyping assay in the pig using SNPs identified and characterized by next generation sequencing technology. PLoS One. 2009;4:e6524 http://dx.plos.org/10. 1371/journal.pone.0006524.

31. Watson M. Illuminating the future of DNA sequencing. Genome Biol. 2014;15:108
32. Loman NJ, Watson M. Successful test launch for nanopore sequencing Nat Methods. 2015;12:303-4 http://www.nature.com/doifinder/10.1038/ nmeth.3327.

33. Florini JR, Ewton DZ, Coolican SA. Growth hormone and the insulin-like growth factor system in myogenesis. Endocr Rev. 1996;17:481-517 https:// doi.org/10.1210/edrv-17-5-481.

34. Van Laere A-S, Nguyen M, Braunschweig M, Nezer C, Collette C, Moreau L, et al. A regulatory mutation in IGF2 causes a major QTL effect on muscle growth in the pig. Nature. 2003;425:832-6 http:/www.nature.com/articles/nature02064.

35. Pursel VG, Hammer RE, Bolt DJ, Palmiter RD, Brinster RL. Expression of growth hormone transgenes in swine. https://www.poultryscience.org/ docs/pba/1952-2003/1990/1990\%20Pursel.pdf. Accessed 30 Oct 2018.

36. Pursel VG, Wall RJ, Mitchell AD, Elsasser TH, Solomon MB, Coleman ME, et al. Expression of insulin-like growth factor-l in skeletal muscle of transgenic swine. 1999. https://the-eye.eu/public/Books/Medical/texts/\%2110trans.pdf. Accessed 30 Oct 2018

37. Pursel VG, Pinkert CA, Miller KF, Bolt DJ, Campbell RG, Palmiter RD, et al. Genetic engineering of livestock. Science. 1989;244:1281-8.

38. Waltz E. First genetically engineered salmon sold in Canada. Nature. 2017; 548:148 http://www.nature.com/doifinder/10.1038/nature.2017.22116.

39. Lai L, Kang JX, Li R, Wang J, Witt WT, Yong HY, et al. Generation of cloned transgenic pigs rich in omega-3 fatty acids. Nat Biotechnol. 2006;24:435-6 http://www.nature.com/articles/nbt1198.

40. Fiester A. Why the omega-3 piggy should not go to market. Nat Biotechnol. 2006;24:1472-3 http://www.nature.com/articles/nbt1206-1472.

41. Zhang P, Zhang Y, Dou H, Yin J, Chen Y, Pang X, et al. Handmade cloned transgenic piglets expressing the nematode fat-1 gene. Cell Reprogram. 2012;14:258-66.

42. Liu X, Pang D, Yuan T, Li Z, Li Z, Zhang M, et al. N-3 polyunsaturated fatty acids attenuates triglyceride and inflammatory factors level in hfat-1 transgenic pigs. Lipids Health Dis. 2016;15:89 https://doi.org/10. 1186/s12944-016-0259-7.

43. Li M, Ouyang H, Yuan H, Li J, Xie Z, Wang K, et al. Site-specific Fat-1 knockin enables significant decrease of $n-6 P U F A s / n-3 P U F A s$ ratio in pigs. Genetics. 2018:8:1747-54.

44. Golovan SP, Meidinger RG, Ajakaiye A, Cottrill M, Wiederkehr MZ, Barney DJ, et al. Pigs expressing salivary phytase produce low-phosphorus manure. Nat Biotechnol. 2001;19:741-5 http://www.nature.com/articles/nbt0801_741.

45. Zhang X, Li Z, Yang H, Liu D, Cai G, Li G, et al. Novel transgenic pigs with enhanced growth and reduced environmental impact. elife. 2018;7 https:// doi.org/10.7554/eLife.34286.

46. USDA ERS - Impacts of the 2014-2015 highly pathogenic avian influenza outbreak on the U.S. poultry sector. https://www.ers.usda.gov/publications/ pub-details/?pubid=86281. Accessed 30 Oct 2018.

47. Donatelli I, Castrucci MR, De Marco MA, Delogu M, Webster RG. Humananimal interface: the case for influenza interspecies transmission. Adv Exp Med Biol. 2016:972:17-33.

48. Lyall J, Irvine RM, Sherman A, McKinley TJ, Nunez A, Purdie A, et al. Suppression of avian influenza transmission in genetically modified chickens. Science. 2011; 331:223-6.

49. Luo G, Danetz S, Krystal M. Inhibition of influenza viral polymerases by minimal viral RNA decoys. J Gen Virol. 1997;78:2329-33.

50. Maga EA, Cullor JS, Smith W, Anderson GB, Murray JD. Human lysozyme expressed in the mammary gland of transgenic dairy goats can inhibit the growth of bacteria that cause mastitis and the cold-spoilage of milk Foodborne Pathog Dis. 2006;3:384-92.

51. Maga EA, Sargent RG, Zeng H, Pati S, Zarling DA, Oppenheim SM, et al. Increased efficiency of transgenic livestock production. Transgenic Res. 2003:12:485-96

52. Wall RJ, Powell AM, Paape MJ, Kerr DE, Bannerman DD, Pursel VG, et al. Genetically enhanced cows resist intramammary Staphylococcus aureus infection. Nat Biotechnol. 2005;23:445-51.

53. Grobet $L$, Royo Martin $L$, Poncelet $D$, Pirottin D, Brouwers B, Riquet J, et al. A deletion in the bovine myostatin gene causes the double-muscled phenotype in cattle. Nat Genet. 1997;17:71-4.

54. Kambadur R, Sharma M, Smith TP, Bass JJ. Mutations in myostatin (GDF8) in double-muscled Belgian blue and Piedmontese cattle. Genome Res, 1997:7:910-6.

55. Clop A, Marca F, Takeda H, Pirottin D, Tordoir X, Bibé B, et al. A mutation creating a potential illegitimate microRNA target site in the myostatin gene affects muscularity in sheep. Nat Genet. 2006;38:813-8. 
56. Proudfoot C, Carlson DF, Huddart R, Long CR, Pryor JH, King TJ, et al. Genome edited sheep and cattle. Transgenic Res. 2015;24:147-53.

57. Crispo M, Mulet AP, Tesson L, Barrera N, Cuadro F. dos Santos-Neto PC, et al. efficient generation of myostatin knock-out sheep using CRISPR/Cas9 technology and microinjection into zygotes. PLoS One. 2015;10:e0136690. https://doi.org/10.1371/journal.pone.0136690.

58. Wang X, Niu Y, Zhou J, Zhu H, Ma B, Yu H, et al. CRISPR/Cas9-mediated MSTN disruption and heritable mutagenesis in goats causes increased body mass. Anim Genet. 2018;49:43-51 https://doi.org/10.1111/age.12626.

59. Khalil K, Elayat M, Khalifa E, Daghash S, Elaswad A, Miller M, et al. Generation of myostatin gene-edited channel catfish (Ictalurus punctatus) via zygote injection of CRISPR/Cas9 system. Sci Rep. 2017;7:7301 http://www.nature.com/ articles/s41598-017-07223-7.

60. Kang J-D, Kim S, Zhu H-Y, Jin L, Guo Q, Li X-C, et al. Generation of cloned adult muscular pigs with myostatin gene mutation by genetic engineering. RSC Adv. 2017;7:12541-9 https://doi.org/10.1039/C6RA28579A.

61. Wang K, Tang X, Xie Z, Zou X, Li M, Yuan H, et al. CRISPR/Cas9-mediated knockout of myostatin in Chinese indigenous Erhualian pigs. Transgenic Res. 2017;26:799-805 https://doi.org/10.1007/s11248-017-0044-z.

62. Cai C, Qian L, Jiang S, Sun Y, Wang Q, Ma D, et al. Loss-of-function myostatin mutation increases insulin sensitivity and browning of white fat in Meishan pigs. Oncotarget. 2017;8:34911-22 https://doi.org/10.18632/oncotarget.16822.

63. Bi Y, Hua Z, Liu X, Hua W, Ren H, Xiao H, et al. Isozygous and selectable marker-free MSTN knockout cloned pigs generated by the combined use of CRISPR/Cas9 and Cre/LoxP. Sci Rep. 2016;6:31729 http://www.nature.com/ articles/srep31729.

64. Rao S, Fujimura T, Matsunari H, Sakuma T, Nakano K, Watanabe M, et al. Efficient modification of the myostatin gene in porcine somatic cells and generation of knockout piglets. Mol Reprod Dev. 2016;83:61-70 https://doi. org/10.1002/mrd.22591.

65. Wang K, Ouyang H, Xie Z, Yao C, Guo N, Li M, et al. Efficient generation of myostatin mutations in pigs using the CRISPR/Cas9 system. Sci Rep. 2015;5: $16623 \mathrm{http}: / /$ www.nature.com/articles/srep16623.

66. Cyranoski D. Super-muscly pigs created by small genetic tweak. Nature. 2015;523:13-4 http://www.nature.com/doifinder/10.1038/523013a.

67. Kang Q, Hu Y, Zou Y, Hu W, Li L, Chang F, et al. Proceedings, 10th World Congress of Genetics Applied to Livestock Production. Improving pig genetic resistance and muscle production through molecular biology. https://www.asas.org/docs/default-source/wcgalp-proceedings-oral/362_ paper_10607_manuscript 1526_0.pdf?sfvrsn=2. Accessed 30 Oct 2018.

68. Matika O, Robledo D, Pong-Wong R, Bishop SC, Riggio V, Finlayson H, et al. Balancing selection at a premature stop mutation in the myostatin gene underlies a recessive leg weakness syndrome in pigs. bioRxiv. 2018:442012 https://doi.org/10.1101/442012.

69. Welfare implications of dehorning and disbudding cattle. 2014. https:// www.avma.org/KB/Resources/LiteratureReviews/Pages/Welfare-Implicationsof-Dehorning-and-Disbudding-Cattle.aspx. Accessed 30 Oct 2018.

70. Gottardo F, Nalon E, Contiero B, Normando S, Dalvit P, Cozzi G. The dehorning of dairy calves: practices and opinions of 639 farmers. J Dairy Sci. 2011;94:5724-34.

71. Thompson NM, Widmar NO, Schutz MM, Cole JB, Wolf CA. Economic considerations of breeding for polled dairy cows versus dehorning in the United States. J Dairy Sci. 2017;100:4941-52 https://doi.org/10.3168/jds.2016-12099.

72. Medugorac I, Seichter D, Graf A, Russ I, Blum H, Göpel KH, et al. Bovine polledness - an autosomal dominant trait with allelic heterogeneity. PLoS One. 2012;7:e39477 https://doi.org/10.1371/journal.pone.0039477.

73. Rothammer S, Capitan A, Mullaart E, Seichter D, Russ I, Medugorac I. The 80-kb DNA duplication on BTA1 is the only remaining candidate mutation for the polled phenotype of Friesian origin. Genet Sel Evol. 2014;46:44 https://doi.org/10.1186/1297-9686-46-44.

74. Carlson DF, Lancto CA, Zang B, Kim E-S, Walton M, Oldeschulte D, et al. Production of hornless dairy cattle from genome-edited cell lines. Nat Biotechnol. 2016;34:479-81 http://www.nature.com/articles/nbt.3560.

75. Sonstegard TS, Carlson D, Lancto CA, Fahrenkrug SC. Precision animal breeding as a sustainable, non-GMO solution for improving animal production and welfare. 2016. https://www.semanticscholar.org/paper/ Precision-Animal-Breeding-as-a-Sustainable-\%2C-for-Sonstegard-Carlson/ f313ec14d15a3be1f8fa6475485308dfe1dd0522. Accessed 30 Oct 2018

76. Große-Brinkhaus C, Storck LC, Frieden L, Neuhoff C, Schellander K, Looft C, et al. Genome-wide association analyses for boar taint components and testicular traits revealed regions having pleiotropic effects. BMC Genet. 2015;16:36.
77. Rowe SJ, Karacaören B, de Koning D-J, Lukic B, Hastings-Clark N, Velander I, et al. Analysis of the genetics of boar taint reveals both single SNPs and regional effects. BMC Genomics. 2014;15:424 https://doi.org/10.1186/14712164-15-424.

78. Wargelius A, Leininger S, Skaftnesmo KO, Kleppe L, Andersson E, Taranger $\mathrm{GL}$, et al. Dnd knockout ablates germ cells and demonstrates germ cell independent sex differentiation in Atlantic salmon. Sci Rep. 2016;6:21284 http://www.nature.com/articles/srep21284.

79. Park K-E, Kaucher AV, Powell A, Waqas MS, Sandmaier SES, Oatley MJ, et al. Generation of germline ablated male pigs by CRISPR/Cas9 editing of the NANOS2 gene. Sci Rep. 2017;7:40176 http://www.nature.com/articles/ srep40176.

80. Taylor L, Carlson DF, Nandi S, Sherman A, Fahrenkrug SC, McGrew MJ. Efficient TALEN-mediated gene targeting of chicken primordial germ cells. Development. 2017:144:928-34.

81. Blesbois E, Seigneurin F, Grasseau I, Limouzin C, Besnard J, Gourichon D, et al. Semen cryopreservation for ex situ management of genetic diversity in chicken: creation of the French avian cryobank. Poult Sci. 2007;86:555-64.

82. Nandi S, Whyte J, Taylor L, Sherman A, Nair V, Kaiser P, et al. Cryopreservation of specialized chicken lines using cultured primordial germ cells. Poult Sci. 2016;95:1905-11.

83. Nakamura Y. Avian Biotechnology. Adv Exp Med Biol. 2017;1001:187-214.

84. Woodcock ME, Idoko-Akoh A, McGrew MJ. Gene editing in birds takes flight. Mamm Genome. 2017;28:315-23 https://doi.org/10.1007/s00335-017-9701-z.

85. Boddicker NJ, Bjorkquist A, Rowland RR, Lunney JK, Reecy JM, Dekkers JC. Genome-wide association and genomic prediction for host response to porcine reproductive and respiratory syndrome virus infection. Genet Sel Evol. 2014:46:18

86. Lough G, Hess A, Hess M, Lunney J, Rowland BB, Kyriazakis I, et al. Harnessing longitudinal information to identify genetic variation in tolerance of pigs to porcine reproductive and respiratory syndrome virus. Genet Sel Evol. 2018;50:50. https://doi.org/10.1186/s12711-018-0420-z.

87. Boddicker NJ, Garrick DJ, Rowland RRR, Lunney JK, Reecy JM, Dekkers JCM. Validation and further characterization of a major quantitative trait locus associated with host response to experimental infection with porcine reproductive and respiratory syndrome virus. Anim Genet. 2014:45:48-58.

88. Koltes JE, Fritz-Waters E, Eisley CJ, Choi I, Bao H, Kommadath A, et al. Identification of a putative quantitative trait nucleotide in guanylate binding protein 5 for host response to PRRS virus infection. BMC Genomics. 2015;16:412.

89. Van Gorp H, Van Breedam W, Van Doorsselaere J, Delputte PL, Nauwynck HJ. Identification of the CD163 protein domains involved in infection of the porcine reproductive and respiratory syndrome virus. J Virol. 2010;84:3101-5.

90. Whitworth KM, Rowland RRR, Ewen CL, Trible BR, Kerrigan MA, Cino-Ozuna $A G$, et al. Gene-edited pigs are protected from porcine reproductive and respiratory syndrome virus. Nat Biotechnol. 2015;34:20-2 http://www.nature. com/doifinder/10.1038/nbt.3434.

91. Yang H, Zhang J, Zhang X, Shi J, Pan Y, Zhou R, et al. CD163 knockout pigs are fully resistant to highly pathogenic porcine reproductive and respiratory syndrome virus. Antivir Res. 2018;151:63-70.

92. Burkard C, Lillico SG, Reid E, Jackson B, Mileham AJ, Ait-Ali T, et al. Precision engineering for PRRSV resistance in pigs: macrophages from genome edited pigs lacking CD163 SRCR5 domain are fully resistant to both PRRSV genotypes while maintaining biological function. PLoS Pathog. 2017;13: e1006206 http://dx.plos.org/10.1371/journal.ppat.1006206.

93. Burkard C, Opriessnig T, Mileham AJ, Stadejek T, Ait-Ali T, Lillico SG, et al. Pigs lacking the scavenger receptor cysteine-rich domain 5 of CD163 are resistant to porcine reproductive and respiratory syndrome virus 1 infection. J Virol. 2018;92 https://doi.org/10.1128/JVI.00415-18.

94. Lu T, Song Z, Li Q, Li Z, Wang M, Liu L, et al. Overexpression of histone deacetylase 6 enhances resistance to porcine reproductive and respiratory syndrome virus in pigs. PLoS One. 2017;12:e0169317 http://dx.plos.org/10. 1371/journal.pone.0169317.

95. Palgrave CJ, Gilmour L, Lowden CS, Lillico SG, Mellencamp MA, Whitelaw CBA. Species-specific variation in RELA underlies differences in NF-KB activity: a potential role in african swine fever pathogenesis. J Virol. 2011:85:6008-14.

96. Lillico SG, Proudfoot C, King TJ, Tan W, Zhang L, Mardjuki R, et al. Mammalian interspecies substitution of immune modulatory alleles by genome editing. Sci Rep. 2016;6:21645 http://www.nature.com/articles/srep21645. 
97. Shanthalingam S, Tibary A, Beever JE, Kasinathan P, Brown WC, Srikumaran S. Precise gene editing paves the way for derivation of Mannheimia haemolytica leukotoxin-resistant cattle. Proc Natl Acad Sci U S A. 2016;113:13186-90.

98. Cheng X, Wang H. Multiple targeting motifs direct NRAMP1 into lysosomes. Biochem Biophys Res Commun. 2012;419:578-83.

99. Gao Y, Wu H, Wang Y, Liu X, Chen L, Li Q, et al. Single Cas9 nickase induced generation of NRAMP1 knockin cattle with reduced off-target effects. Genome Biol. 2017;18:13 https://doi.org/10.1186/s13059-016-1144-4.

100. Anderson RM, May RM. Infectious diseases of humans. Dynamics and control: Oxford University Press; 1991. https://global.oup.com/academic/ product/infectious-diseases-of-humans-9780198540403?cc=gb\&lang=en\&

101. Kimman TG, Cornelissen LA, Moormann RJ, Rebel JMJ, Stockhofe-Zurwieden N. Challenges for porcine reproductive and respiratory syndrome virus (PRRSV) vaccinology. Vaccine. 2009;27:3704-18.

102. Murtaugh MP, Stadejek T, Abrahante JE, Lam TTY, FC-C L. The ever-expanding diversity of porcine reproductive and respiratory syndrome virus. Virus Res. 2010;154:18-30.

103. Shafran D, Kodish E, Tzakis A. Organ shortage: the greatest challenge facing transplant medicine. World J Surg. 2014;38:1650-7.

104. Patience C, Takeuchi Y, Weiss RA. Infection of human cells by an endogenous retrovirus of pigs. Nat Med. 1997;3:282-6.

105. Moalic Y, Blanchard Y, Félix H, Jestin A. Porcine endogenous retrovirus integration sites in the human genome: features in common with those of murine leukemia virus. J Virol. 2006;80:10980-8.

106. Yang L, Güell M, Niu D, George H, Lesha E, Grishin D, et al. Genomewide inactivation of porcine endogenous retroviruses (PERVs). Science. 2015;350:1101-4.

107. Niu D, Wei H-J, Lin L, George H, Wang T, Lee I-H, et al. Inactivation of porcine endogenous retrovirus in pigs using CRISPR-Cas9. Science. 2017; 357:1303-7.

108. Ledford H. Salmon approval heralds rethink of transgenic animals. Nature. 2015;527:417-8 http://www.nature.com/doifinder/10.1038/527417a.

109. Jenko J, Gorjanc G, Cleveland MA, Varshney RK, Whitelaw CBA, Woolliams JA, et al. Potential of promotion of alleles by genome editing to improve quantitative traits in livestock breeding programs. Genet Sel Evol. 2015;47:55.

110. Johnsson M, Gaynor RC, Jenko J, Gorjanc G, de KD-J, Hickey JM. Removal of alleles by genome editing — RAGE against the deleterious load. bioRxiv. 2018:335497 https://doi.org/10.1101/335497. 